\title{
Polycode hypertext in polylingual discourse of intercultural communications
}

\author{
Irina V. Vashunina - Marina E. Ryabova - Liudmila A. Egorova
}

DOI: $10.18355 /$ XL.2018.11.02.17

\begin{abstract}
The article considers linguistic aspects of polycode hypertext functioning in a polylingual context investigating its potential in changing the value orientation of a mass recipient. Hypertext is regarded as a means of communication uniting multilingual streams of conceptual sense, which is represented by means of verbal and non-verbal codes as well as perceptive images of multi-level modalities. Resistance to hidden manipulative influence is an acute problem nowadays. Hypertext as an asymmetric and polymodal phenomenon is seen from the point of view of its functioning in a communicative reality. The psycholinguistic experimental study using the method of semantic differential shows the main trends of creolized hypertext development and perception. Pragmatic potential of different parameters of visual components for manipulation of the public conscience is identified. Polycode text usage changes categorial realia of communication through information perception management resulting in modification of recipients' value orientation.

Key words: communicative reality, hypertext, polycode communication, multilingual mosaic, hypertext asymmetry, creolized text, experimental study, audiovisual communication, value orientation, mass recipient
\end{abstract}

\section{Introduction}

Multilanguage discourse is an ultimately important phenomenon of intercultural communications in modern society. Mankind relates the future to expanding and deepening the sphere of communications. Forming information "hypersystems", this process leads to crucial changes in categorial realia of communication and its global intensification. Its unique speed and scale are represented by information technologies affecting society in general and every person in particular. New ways of involvement of an individual into information flows and linguistic and cultural dynamics come into existence.

Analyzing contemporary theoretical and experimental studies on hypertext, we can distinguish their two major dimensions: theoretical and technical. The first includes the analysis and description of textual and contextual structures that form the hypertext (Kuhlen, 1991; Landow, 2006; Nelson, 1992; Müller, 1990; Wirth, 2002; etc.), the second concerns their technical implementation (Bolter, 1991; Eckkramer, 2004; Engelbarth, 1995; Lanham, 1993). This two-level approach encompasses all the other conceptions, the most impactful of which are the theory of patterns (Grenander and Miller, 2007), computational linguistics (Hausser, 2014), ergonomic semiotics (Nisbett, 2003) and many others.

From the very beginning hypertext has often been regarded as an unlimited information structure, e.g. the concept of "open hypertext" (Nelson, 1992). The idea of dynamically extensible hypertext, which is not a ready-made product, but the thing constantly weaving new meanings in its network, was introduced in the humanities by the philosophy of post-modernism. The fundamentals are the principle of deconstruction (Derrida, 1979), the language of the unconscious (Lakan, 1997), schizoanalysis, the concept of the rhizome (Deleuze, Guattari, 2010), the concept of the "open" text (Eco, 2006).

Overall, the humanitarian approach to media hypertext study can be considered in two ways: on the one hand, "hypertext as media", in which the communicative 
environment of virtuality determines the formation of new cultural paradigms (Castells, 2015; Derrida, 1979; Eco, 2006); and on the other, "polycode hypertext as a special language" - the emergence and functioning of new language systems - signs, symbols, "language games" (for example, so-called "Olbanian language", "Ruglish"), etc.

A real revolution in views on hypertext can be associated with the development of a semiotic approach, which, to our mind, is the most adequate in the analysis of hypertext polycode space. This approach covers all the diversity of sign content and structural features of the hypertext culture communicative resource.

Communicative reality consisting of decomposable fragments of multilingual text of multiculture indicates the need for understanding the factors that accentuate the problem field of nonlinearly structured hypertext and create specific conditions for its philological study. The relevance of the phenomenon of hypertext is firstly derived from the antinomous nature of the whole socio-cultural space, which manifests itself in all sorts of norms uncertainty (cultural, linguistic, axiological and other ones). Secondly, it is due to the ambivalence of the processes associated with flexible transitions from one trend to another. Polycode hypertext potentially allows bringing a lot of meanings together, thus ensuring the integrity of perception. This means that in a complicating society hypertext is becoming an increasingly more essential and effective marker of polycode communication. Therefore, studying multi-layer hypertext leads to a specific field of research, where polycode character of the text and linguistic consciousness of the individual are closely interrelated. This article aims at an explication of some controversy in hypertext culture cognition in linguistics.

\section{Literature Review}

\subsection{Hypertext and Multilingual Communicative Reality}

A significant part of communications takes place in the cognitive discourse of multilingualism, discovering new meanings and representations both in the linguistic worldimage of the individual and within the framework of a "polycode universum". The relationship of complementarity and interdependence between the components of this multilingual reality, developing quantitatively and qualitatively, acquires the outlines of vertically and horizontally connected whole. Multiple referential dependence on reality can correspond to the system accumulating information by retrieving it from various texts, understood in a semiotic sense, i.e. as all kinds of linguistic signs. This system was named hypertext.

Hypertext as a complicated extra-linguistic paradigm can be interpreted as a way of communication in modern society, oriented in multiple, simultaneous multilingual streams of conceptual sense, explicitly represented not only by the units of verbal and nonverbal codes, but also by the perceptual images of multi-level modalities. The ability to take a variety of shapes marks the hypertext as a complex, self-organizing system, containing a huge reservoir of knowledge that a human being can neither learn, nor perceive in full. It is important to note that the emergence of hypertext indicates the formation of non-linear type of thinking arising from new information technology wiping off distance and time limits.

This research highlights the features of hypertext connected with its functioning in multilingual discourse, which allows representing the multi-level process of production and reproduction of other languages' senses. M.E. Ryabova (2007, p. 25) noted that

...in the context of global challenges faced by a transforming society people frequently have to communicate in another language. It leads to forming new mindset, behaviour patterns and values, differently perceived by the communicants as comfortable/ uncomfortable, theirs/not theirs or familiar/new.

XLinguae, Volume 11, Issue 2, April 2018, ISSN 1337-8384, eISSN 2453-711X 
Between different, often opposite, elements of hypertext there is a gap, a contradiction, a conflict, which is the realization of its polyphony. Choice in the context of these complementary structures of knowledge is not clear. Multilingualism as a new universal reality allows us to interpret the world as a linguistic entity, filled with a variety of background codes. The essential intrinsic characteristic of hypertext is instant response capacity together with simultaneous use of redundant means of communication. Hypertext can be regarded as reality intensifying information flows, communication, growth of polycode culture. Hypertext development is the most important manifestation of the human world complexity. This is reflected, on the one hand, in its duality, in its mediation by means of multilingual semantic redundancy, and on the other, in the destruction of the perception integrity. Multilingual fragmentation of knowledge is arising. The elements of such knowledge are interacting on different levels and forming a blurred configuration of subtle meaning. Multilingualism is developing a particular linguistic category associated with modernity, with the intensification of communication flows. This category can be described as a multilingual mosaic that combines random and ordered components. Such a web produces a manifold network structure, a hypertext. Its unequal operation in real and virtual spaces is manifested in the unequal combination of vertical and horizontal coordinates, excessive redundancy of sense. Multi-faced multilingual discourse constantly acquiring new formats is being transformed into an asymmetric audio-visual polycode hypertext.

\subsection{Hypertext Asymmetry}

Gadgets designed for processing large amounts of information in the Internet increase the uncertainty and asymmetry of communication. Hypertext asymmetry encompasses:

(a) coexistence of multilingual horizontal and vertical communication;

(b) superimposition of vertical and horizontal background information stipulated by mental differences of recipients' ethnic cultures;

(c) dominance of audio/visual forms of the text, which are actualized in various contexts of multilingualism;

(d) hypertext dynamics.

Asymmetry is not functional, but the intrinsic essential characteristic of hypertext, on which all hypertextual formations are based. Linguistic and cultural studies examine hypertext asymmetry mainly from a functional point of view as having a great pragmatic potential. The presence of this potential results from the fact that the content of hypertext is not merely a sum of its components. The content of hypertext is an alloy, a synthesis of texts and senses, a result of their interaction.

This leads to the concept of hypertext as an emergent phenomenon. The hypertext emergence allows you to express the essence of the ongoing changes in society more accurately. Every text is included in the circulation of multilingual transformations, so its communication field becomes available directly or indirectly by means of developing technologies, with communication being not potentially, but actually intersubjective at all levels (virtual and real). Hypertext semantic space draws in the diversity of current contexts aimed at direct or indirect addressees, to whom it opposes openly or latently, causing variable associations. The analysis of the hypertext spatial conceptualization has led to the conclusion that '.... hypertext system $<\ldots>$ and its associative links represent a multidimensional information space. This information environment is adequate to the fundamental structure of processing ideas in the human brain' (Egorova, 2011, p. 8). Emerging associative fields lead to the manifestation of emergent properties that affect the conceptual original sense.

The ambiguity of hypertext, its internal contradictory essence in the process of increasing communicative complexity, is a more complex issue. This fact requires investigating the mechanism of forming and overcoming multiplicity. Culture is 
formed as a continuously increasing system of polycode oppositions within the hypertext. The hidden mechanism of this process is as follows. The primary texts are not connected and the opposite poles are always unequal to some extent. This asymmetry embodies the desire of dominance of one over another. That is as may be, but if the poles were absolutely equal, human life would cease in all forms, because this inequality contains the driving force of all trends and demands of every person. Or, rather, all human desires are embodied in contradictory oppositions, in the motion vector of thought and action from one pole to another. Moreover, asymmetry lays the foundation to confront this inequity and neutralize it, which means that every opposition gives impetus to the opposite. And this, in turn, means that there have never been isolated oppositions, as they instantly grow a giant hypertext, where these oppositions form complex texts, stimulating and neutralizing each other at the same time.

Reference to the current contexts and real addressees is one of the conditions of communicativeness: any language exists the communicative space of transformation. The concept of space is mainly associated with the achievements in various fields of knowledge where we see prevailing geometrical, physical, biological, geographical or historical interpretations. When using the term "communicative space" in this research, we specify the content of the category of space associating it with the category of time, where our discussion is focused on.

It should be noted that the interaction of perceptual and cognitive processes provides flexible transitions between multiple codes of multi-lingual image of the world. Such specificity of the hypertext heuristically transforms the asymmetry of communication into a new value base. Analyzing hypertext in terms of its asymmetry, in our opinion, opens new methodological perspectives on the study of new properties of multicultural discourse horizontally, i.e. when the contrary values, leading ultimately to the point of bifurcation, instability and change in the explicative moments of the hypertext, are accumulated.

Thought movement and action through a hypertext is a form of culture, manifesting its internal contradictions and possibilities to overcome them.

Ontology of intercultural communication: polymodality of hypertext

The mechanisms of creation and functioning of hypertext are closely linked with the mental images of language consciousness, represented by means of different modalities when a hypertext is being created. Linguistic consciousness is regarded as 'a collection of consciousness images formed and dementalised with by linguistic means' (Tarasov, 2000, p. 26). Without a doubt, language consciousness is inherent to the consciousness of man. This part of the consciousness of an individual is not closed in itself, but exists in close relationship with their non-linguistic consciousness, and the consciousness of other people. The images of language consciousness originate in the mental activity and are based on views of different modalities. At the same time as a result of interpersonal contacts linguistic consciousness of the individual may change, evolve, and expand, intaking another person's consciousness elements.

Modern science has different ideas about the form of the primary consciousness image. Consciousness image is based on associations arising from the perception of objects. The perception of the object actually flows in different modalities, justifiying the point of view of modern researchers (Anan'ev, 1960; Gostev, 2007), according to which the consciousness image is polymodal with a visual subject image playing the principal role (Anan'ev, 1960).

When the image is dementalized (explicated), the modality for this action should be chosen. The process of dementalization could be either spontaneous (e.g. in a dialogue) or thoughtful and planned (creating most works of art). The choice of dementalization modalities is always conscious. A person predetermines how he is going to express the images of their consciousness: by means of words, music,

XLinguae, Volume 11, Issue 2, April 2018, ISSN 1337-8384, eISSN 2453-711X 
drawing, dance, etc. The emotional fabric of the image, interpreted as 'a generic term for various sensory characteristics and perceptual categories' (Zinchenko, 2010, p. 26) is redundant, so individual outputs are different, which enables to represent the image in different modalities. The same 'consciousness intentionality may give different outputs in processing' (Mamardashvili and Pyatigorskij, 1997, p. 147). However, emerging dementalization correlates with the primary image consciousness. Yu.M. Lotman (1992) notes that each language of different modalities (verbal and iconic) is 'isomorphic in many ways to non-semiotic world of reality' (Lotman, 1992, p. 18).

The process of speech production and perception is impossible without constant 'flows' between linguistic and non-linguistic consciousness. From the addresser's point of view, we have the following schematic picture of the process: immediate data (what we call the consciousness image) is verbalized and non-verbalized in different proportions; there is interpenetration and interrepulsion between these parts. The socalled 'sphere of Between', where verbal and non-verbal components of the image consciousness interact, manifests itself dynamically, which means that non-verbalized components become verbalized, opening new layers of non-verbalized ones, helping them to "float" to the level of the needs and capacity of adequate verbalization. Synchronistic view of consciousness, forming thoughts, 'reveals two levels of current subjective reality: non-verbalized and verbalized' (Dubrovskij, 2002, p. 77).

The addressee receives and interprets a verbal message, but 'the thoughts generated by the semantic perception of the verbal messages are formed each time anew, here and now, and have not existed in this particular configuration previously' (Tarasov, 2000). According to E.F. Tarasov (2000), 'no content is communicated as consciousnes', it is to arise. If communication is successful, the content of the verbal message invokes consciousness operation (if it does not, then communication cannot be successful) and becomes the content of the addressee's consciousness in a modified form (which is inevitable when you create a new content). The addressee enters a state of linguistic consciousness, trying to understand the verbal message through the meaning of the words. V.P. Zinchenko (2010) mentioned that 'a word can generate an idea that does not fit in the word and goes beyond its limits'. The addressee can get into non-linguistic consciousness by means of words. It is difficult to distinguish between linguistic and non-linguistic consciousness as 'the ability to think without words is empowered by the word itself' (Zinchenko, 2010). Therefore, the operation of consciousness is tied to the word (in this sense, language awareness), going beyond it in a way.

The addressee under the operation of non-linguistic consciousness as a result of the verbal message perception, can verbalize the contents of their consciousness (e.g. in communication), i.e. start the process described by D.I. Dubrovsky (2002). The content of the image is not fully explicated, as each language has its limitations. Emerging in human consciousness images may have features of different modalities, with principal visual modality, as mentioned above. Verbal and iconic languages are not isomorphic. Verbal language is poorly adapted to the expression of spatial relationships, geometric forms and colours. R.M. Frumkina (1984) showed that there are differences in the perception of colour swatches and colour names. Mood is expressed better by means of music and colour than words. Tactile sensations are often verbalized by reference to the specimen (soft like a pillow, carpet, touch - each time there are different sensations difficult to describe with words). It is obvious that any content can be verbalized, i.e. correlated with the content of linguistic units, with varying degrees of completeness and accuracy.

\subsection{Trends in Creolized Hypertext Development}

On the basis of the hypothesis about the potential verbalization of non-verbal (visual) characteristics and their influence on the perception of the verbal text, we studied the perception of creolized texts, i.e. verbal texts with illustrations. "Creolized text" 
contains components of different sign systems, which form an indivisible unity, alloy. By origin it is possible to distinguish two types of creolized texts: natural and artificial. The Internet communication produces artificial texts.

Artificial creolized texts are a synthesis of (macro) components, which can exist separately. These are the texts of various arts (music, theatre, cinema), advertising, illustrated verbal texts and, certainly, the Internet texts. All the macro components of artificial creolized texts are obligatory. However, this obligatoriness is different in comparison with natural texts. Natural texts are characterized by functional obligatoriness when all the components exist as members of functional unities: sounding word - timbre -tone - intonation; the grapheme - font - placement on the page. Obligatoriness of artificial texts is intrinsic. Their components can exist by themselves, but the exception of one component completely destroys the creolized text and leaves two or more separate texts-components: music without dance, words without music, drawings without captions, etc. The object changes its nature: a song becomes a poem, an advertisement turns into a picture and so on.

Artificial creolized texts are complex entities, whose macro components consist of simple artificial and pseudo-natural texts. The texts in the artificial creolized texts are pseudo-natural, as the use of natural texts in this case is impossible. Any dialogue from the play or the film, any movement, any text will be specially designed (perhaps on the basis of the mechanism of synesthesia) and not a spontaneous result of the action of synesthesia. All these texts are created consciously. The number of epiphenomena in them tends to zero. Voice timbre, for example, will be a component of an artificial creolized text as much as volume, as the text production selects "the bearer" of the corresponding timbre.

Language consciousness declares itself if a creolized text includes a verbal text. To create a synthetic phenomenon, the author needs to relate the phenomena of one modality to the phenomena of another, to translate from one language into another. This process involves consciousness.

Components of creolized texts tend to belong to different authors: a verbal text may belong to one author, music to another, dance to a third one. However, when a text becomes creolized, it has just one author (though creative unions may arise). The author is the creator of a creolized text as a whole or the person completing the process of its creation. In illustrated texts the author of a creolized text is the artist, as a creolized text had not existed until he started his work. The artist, perceiving a verbal text, forms the images of non-linguistic consciousness, dementalized, in this case, by non-linguistic means. The recipient of a creolized text, created by an artistillustrator, will act as an artist who perceives a verbal text and forms the images of non-linguistic consciousness, but under the limitations imposed by the illustration. That is, the process of broadcasting the content of the verbal text can be divided into several stages: 1) selection of the visualized content by the creator of the visual image, 2) his choice of image parameters, 3) the perception of a visual image by a recipient 4) building the text content on reading the verbal text. No content is transmitted as consciousness, but is re-formed in the mind of the recipient, whose consciousness may undergo manipulation by means of multimodal explications in any content transmission. In fact, the distortion of the content of the verbal text (for example, for manipulation) could occur at one of the two stages of creating a multimodal text.

In the first stage, the creator of the text selects the information to be visualized in the verbal text. Since it is usually impossible to illustrate the content of the verbal text in full, the situation of multiple choice is bound to arise. Theoretically, only essential elements connected with the theme and plot of the text should be selected and presented in different modalities. However, in practice the implementation of these intentions is not so straightforward. Discrepancies may occur in the wording of the topic, highlighting the important and unimportant, identifying the plot lines. Even if

XLinguae, Volume 11, Issue 2, April 2018, ISSN 1337-8384, eISSN 2453-711X 
the creator of the text has no (manipulative) purposes, his interpretation of the verbal text may differ from the interpretations of the same text by other people, including the "mainstream" interpretation (conventionally understood as the interpretation by most recipients).

Manipulative intentions can be realized extensively when selecting the content for visualization. Marginal elements can be singled out, some details absent in the verbal text can be added to the image, the image range can be built up in a special way (creating new relationship between images inconsistent with the relationships between verbal elements in the text). Let alone the illustration of the sequel, by contiguity or similarity. Skillful use of different techniques and codes can change the content of the verbal text greatly.

In the second stage, another option of the text content changes is the use of visual parameters of the image. All these settings: colour, shape, location in space, style and delivery have their own semantics.

The hypertext creator aims at providing the user with certain information in a convenient and clear way so that they could use it effectively. That is, the creator originally starts from the information requiring a visual representation. The process of perception takes place in the reverse order: first the recipient perceives visual information presented on the display and on interpreting it as a pattern of actions, starts to "unzip" the contents. A. Dillon (2000, p. 525-526) describes this model as follows:

The information display is perceived by the user who then creates a dynamic working model of the information space contingent on current contents and their format. Relevant spatial attributes (layout, image placement, length of text, window size, navigation icons etc.) combine with activated memories of just processed information as well as semantic attributes of the information genre applied top-down (expected form, style, sequencing, meaning etc.) to create a continuously updated and modifiable dynamic representation of the information space for this interactive task.

For the average user, a clear and understandable visual design of the display space is essential, because, as A. Dillon (2000, p. 523) notes, 'experts could process semantics of the visual information space, while novices, lacking the appropriate knowledge base, had to rely solely on spatial cues'. The role of visual parameters for nonspecialists is decisive, which makes the influence of these parameters on the information perception worth examining.

\section{Research Methodology \\ 3.1. Materials and Methods}

In order to study the contradictions in the creolized hypertext perception, a psycholinguistic experiment was carried out. For the sake of clarity, we deliberately selected simplified creolized text (not hypertext) for the experiment. Its main goal was to compare discrepancies in the perception of creolized texts consisting of verbal texts (of different styles and genres) and different (in the manner of performance, geometric forms, colour) illustrations. The same verbal text was presented to recipients along with a variety of illustrations and had to be evaluated on scales of semantic differential, a total of 50 (Vashunina, 2009). During the analysis of the experimental results the scales were grouped according to the factors (in accordance with the loading). A total of six factor structures were singled out labeled "Text Content Evaluation", "Text Expressiveness Evaluation", "Emotional Response", "Comfort", "Activity" and "Potency".

Referents were undergraduate students of different specialities (philologists, historians, chemists, biologists, physicists, mathematicians, economists, athletic trainers). 811 female questionnaires and 712 male questionnaires (total of 1523) were analyzed. 
As a verbal component, we chose popular science, literary prose and poetry texts. Our choice was motivated by the presence of different types of information and varying degrees of imagery in these texts. Text information of different types requires different visualization potential, which should affect the perception of creolized texts (CT).

The main criterion for the selection of texts was the condition for the unambiguous definability of the text theme. The answer of all the respondents to the question about a verbal text from our experimental material "What is the text about?" was "about a snake" or "about the Urals" without hesitation. First, both objects are perceived by the recipient from a distance. Secondly, the respondents are certain to have some information about these objects (if for no other reason than because they are studied at school), and therefore, verbal texts are comprehensible and are not the only source of information. Thirdly, we expected a different attitude of recipients to the selected objects of description. The topic "Ural" can be considered neutral, while the prejudice against snakes is widely known. Fourthly, the formal possibilities of illustrating texts are different. Evidently, the illustrations for the texts on "Ural" must contain angular forms, and on "snake" - rounded ones. The study aimed at determining the influence of geometric forms on the evaluation of CT. The fact that the natural colours of both objects are colours of minor gamut (see below for the term "minor"), allows identifying the relevance of matching the color gamut and geometric shapes. When illustrating selected verbal texts, we got a combination of minor colour gamut with harmonious rounded geometric shapes (on the topic "snake") and disharmonious angular forms (on Ural).

Thus, the primary material comprised six verbal texts in Russian (A4):

two popular science texts on both subjects taken from the Great Soviet Encyclopedia (Mukhin, 1977, p. 56 - 60); Snake (Terent'ev, 1973, p. 545);

two prose texts - an excerpt about Ural from E.A. Fedorov's (1987) Stone belt and about the snake from T.M. Reid's (1957) The Young Yagers; or, A Narrative of Hunting Adventures in Southern Africa.

two poetic texts - an excerpt from N.A. Zabolotsky's (1985) poem "Ural" and I.A. Bunin's (1977) poem "The Snake".

Each of the six texts had five illustrations. Two of them were made in a realistic manner. The realistic illustrations were a graphic black-and-white drawing and a painting (based on the drawing) in colours of nature. The other three illustrations were symbolic or contained symbolic elements. When creating these illustrations, the artists were not restricted in manner of performance, therefore, illustrations of different styles were selected for different texts. These three illustrations were labeled fantastic. The basis of three fantastic illustrations is one drawing executed in three versions: in black and white, in a minor gamut (shades of blue, green, purple, brown) and in a major gamut (shades of red, orange, yellow). The terms "minor" and "major" in relation to colours are used on basis of their transferred meanings connotations in Russian "sad" and "happy, upbeat", respectively (Ushakov, 2000), because these connotations correlate with the common perception of colour groups by the recipients. Thus, each primary verbal text was the ground for five creolized ones forming a group. A total of six groups (the number of verbal texts) were created.

The material for the presentation to the respondents consisted of two glued A4 sheets. A verbal text was printed on the left sheet, a full-page illustration - on the right one.

The content of verbal texts presented as experimental material cannot be fully translated into visual language. However, all the texts clearly define the basic objects: Ural and a snake. The word "Ural" conjures up visions of a cool, harsh land: mountains, rivers, pine forests, rocks, industrial plants, which is associated with green, blue, blue, gray colours and broken, angular forms. A snake is associated with round shapes. Nature colors are neutral - grey, brown, greenish. Minor gamut colours can be

XLinguae, Volume 11, Issue 2, April 2018, ISSN 1337-8384, eISSN 2453-711X 
considered natural colours to represent the concepts of "Ural" and "snake". Colours of individual illustrations matched object representations to different extents.

\subsection{Research Procedures}

The experimental procedure was a CT assessment on SD scales. This method is characterized in several papers (Levandovskij, 1980; Petrenko, 2005; Shmelev, 1982a; 1982b; 1983). The semantic differential technique has been successfully applied for identifying the relationship of the recipient to various objects and phenomena. The advantage of the semantic differential method is that 'one of the unique features of SD is that attitudes to a wide range of objects can be measured from the point of view of basically the same metric on the three EPA dimensions' (Heise, 1970, p. 249). This method is based on universal features of information perception and can be used to study different linguocultures. L.A. Jakobovits (1966, p. 26) commented, 'The fact that each pan-cultural factor is defined by scale loadings of comparable size across all languages proves the true pan-cultural nature of the semantic space as measured by these procedures' (cited in Heise 1970, p. 237). The proposed scales resulted from an experimental selection. The group of respondents (a total of 198 respondents) were asked to describe the chosen verbal texts using any definition. Then the most common characteristics were identified. Using the dictionaries of synonyms (Aleksandrova, 1999), we defined a synonymic dominant and formed the basis for the scale. If the antonym was among the characteristics of the texts, the scale was complete (e.g. "anxious" - "calm"). Otherwise, we consulted dictionaries of antonyms (L'vov, 2002; Vvedenskaya, 2004). As the scales were selected on the basis of the definitions proposed by respondents, the complete list did not include some classic SD scale (e.g., "sharp - dull"). We can assume that they are not relevant to the six selected texts.

For the experimental study, we developed a 50-scale SD. The left pole of SD is the concept, indicating the lack of quality or less amount of quality, and on the right one lies the concept, indicating the presence of quality or greater amount of quality. A traditional, seven-point $(-3$ to +3$)$ scale was used. Respondents were shown a CT with the instruction: "Could you rank the proposed text according to each parameter, placing the + in the box corresponding to your rating?"

Results

The experimental data were processed with Principal Component Analysis and Varimax with Kaiser Normalization. Six factor structures and the loading of the scales on these factors were identified. As V.F. Petrenko (2005) mentioned, 'the labeling of the factors is rather conditional', so if it was impossible to combine factor structure scales under one general label, the factors were labeled by one of the scales with the most general meaning.

The following factors were selected: "Text Content Evaluation", "Text Expressiveness Evaluation", "Emotional Response" (corresponding to the traditional factor of "Evaluation"), "Comfort", "Activity" and "Potency". The following scales were included in the individual factors. The scales "Sluggish - Energetic" and "Bad Good" have a significant loading (we considered a loading greater than 0.4 significant) on two factors, so they are listed for both factors including them. The near-zero number of scales that can be attributed to different factors indicates a high independence of the selected factors, therefore, it is possible to assume that assessments by means of different factors characterize different aspects of CT perception. The resulting list of the factors contains the scales ranging from maximum loading on the factor (the first member of the structure) to minimum loading (the last member of a structure).

The leading factor of "Text Content Evaluation" includes the following 13 scales (dominating in 12): "false - true" (.753 loading), "wrong - correct," "unnecessary necessary", "frivolous - serious," "illogical - logical", "silly - clever", "harmful - 
beneficial" "fantastic - real," "meaningless - meaningful", "abstract - concrete", "blurry - sharp", "unfair - fair", "bad - good" (.401 loading).

The factor of "Text Expressiveness Evaluation" dominates in the following 10 scales: "pale - bright" (.754 loading), "commonplace - original", " inexpressive expressive", "lifeless - vivid", "uninteresting - interesting", "usual - unusual", "poor rich", "repulsive - attractive", "sluggish - energetic", "ugly - beautiful" (.512 loading).

The factor of "Comfort" dominates in the following 7 scales. The label of the factor was introduced by V.F. Petrenko (2005), though the structure of the factor in the previous studies is not quite consistent with ours. The factor of "Comfort" includes the scales "heavy - light" (.713 loading), "hard - soft", "dark - bright", "cold - warm", "anxious - relaxed", "old - young", "far - close" (.408 loading).

The factors of "Emotional Response", "Activity", "Potency" coincide with the traditional factors of "Evaluation", "Activity", "Potency" though have a specific structure.

The factor of "Emotional Response" was the fourth, dominating in the following 7 scales: "hostile - friendly" (.782 loading), "evil - good", "rough - gentle", "negative positive", "nasty - nice", "sad - joyful", "good - bad" (.435 loading).

The factor of "Activity" consists of the following 7 scales (dominating in 6): "calming - exciting" (.796 loading), "quiet - loud", "slow - fast", "immobile - mobile", "tired alert", "sluggish - energetic", "relaxed - tense" (.401 loading).

The factor of "Potency" dominates in the following 6 scales: "simple - complex" (.724 loading), "small - big", " superficial - deep", "narrow - wide", "sparse - dense" (.462 loading).

\section{Results and Discussion}

The results of this experimental study allow making the following conclusions. The selection of C. Osgood, M.S. MIRON and W.H. May's factors (1975) of "Evaluation", "Activity", "Potency" confirms that these structures are "universal factors that reflect ... the global categories of our world classification and are manifested in building almost any semantic space' (Petrenko, 2005; Etkind, 1979). According to V.F. Petrenko (2005):

'When working with a narrower, semantically homogeneous class of objects, particular bases for the classification mediated by the respondents' knowledge about the class of the objects, because of their repetitiveness inside this class, have a significant influence on the dispersion and are displayed as factors. Thus, the semantic space built on the basis of estimates of a narrow semantic class of objects is characterized by higher dimensionality (number of selected factors) on the one hand, and a greater focus on the substantive, embodied in the meaning, features of objects, on the other hand. In other words, it will contain more subject-oriented components of this space along with the connotative (emotional and evaluative) factors" (Petrenko, 2005, p. 100).

The analysis of the creolized texts evaluation proved that there was a change in the text perception under the influence of the illustrative element. Creolized texts containing the same verbal component, but different illustrations are assessed differently. The dynamics of assessments helped to determine image parameters affecting the evaluation of the text on separate scales. These are realism, clarity, nontriviality of the image, usage of certain geometric shapes and colours (minor and major scales, achromatic colours in graphic illustrations), consistency among the colour design, text content and geometric forms. Largely, this means that the perception of the text as more or less meaningful, positive, young, close, strong, etc. depends (for each scale individually) on how realistic, understandable, and trivial illustrations are, whether rounded or angular geometric shapes, minor (blue-green,

XLinguae, Volume 11, Issue 2, April 2018, ISSN 1337-8384, eISSN 2453-711X 
purple) or major (red-yellow-orange) colours have been used. For example, a creolized text with a strange illustration (i.e. unclear object attribution of individual components) is perceived not only as weird, but as more false, stupid, unfair. The text with an angular, sharp image is assessed as anxious, hostile and angry.

Varying visual parameters of the image it is possible to control the perception of information. What is important is that the recipients are not aware of this impact and do not regard it as manipulation. Even if the recipient is inclined to consider the text critically, he will not be free from the influence of the form and will not be able to identify it and separate from the content of the verbal text. The extensive use of visual parameters of the image (in the manipulative purposes) ultimately could lead to the change of the mass recipient value orientations. These experimental findings suggest the hypothesis that if even a simple creolized text has a latent power of manipulating the perception of the subject, a creolized hypertext should be a powerful tool of the recipient's axiological system formation.

\section{Conclusion}

To sum up, it can be stated that multilingual hypertext is a qualitatively new way of communication, the study of its properties and functionality being at the beginning. Hypertext should be seen as an emergent phenomenon, the meaning of which is not a simple sum of its parts. Contradictions of multilevel coordinate axes lead to the building up of the hypertext meanings, which can cross the bifurcation point and lead to the formation of a new sense at any moment. Arising additional and new meanings can change the value orientation of the individual and mass recipients, imperceptibly though sharply and quickly. Such changes in values are caused by a polycode character of hypertext, as well as its multilingualism in connection with wiping off boundaries and temporal distance between the recipients. The hypertext has its own culture of communication with its own preferences and values, which ultimately makes hypertext a new medium of communication. A new culture of a new phenomenon - hypertext - affects the mental images of the individual consciousness and the value orientation of society as a whole and generally can be considered as regards manipulation of public consciousness.

\section{Acknowledgements}

The publication has been prepared with the support of the "RUDN University Program 5-100".

\section{Bibliographic references}

ALEKSANDROVA, Z.E. 1999. Slovar' sinonimov russkogo yazyka: prakticheskij spravochnik. Moscow: Russkij yazyk. ISBN 5-200-02774-8

ANAN'EV, B.G. 1960. Psihologiya chuvstvennogo poznaniya. Moscow: RSFSR Publishers. ISBN 0877193452

BOLTER, J.D. 1991. Writing space: the computer, hypertext, and the history of writing. Lawrence Erlbaum Associates. New Jersey: Hillsdale. ISBN 0-8058-0427-7

BUNIN, I.A. 1977. Izbrannoe: Stihotvoreniya. Perevody. Moscow: Moskovskij rabochij. ISBN 19954-2537.

CASTELLS, M. 2015. Networks of outrage and hope: social movements in the Internet age. Cambridge: Polity Press. ISBN: 978-0-745-69576-1

DELEUZE, G. - Guattari, F. 2010. Tysyacha plato: kapitalizm i shizofreniya. Ekaterinburg: U-Faktoriya. ISBN: 978-5-9757-0526-6, 978-5-271-27869-3

DERRIDA, J. 1979. Living on. In: H. Bloom et al. (eds.) Deconstruction and Criticism. London: Routledge and Kegan Paul. ISBN 0-415-22930-8

DILLON, A. 2000. Spatial semantics and individual differences in the perception of shape in information space. In: Journal of the American Society for Information Science, vol. 51, n. 6, 521-528. ISSN: 2330-1643. 
DUBROVSKIJ, D.I. 2002. Problema ideal'nogo. Sub"ektivnaya real'nost'. Moscow: Kanon+ Publishers. ISBN 5-88373-155-4

ECKKRAMER, E.M. 2004. Von Konversionen, Transpositionen und Multimodalität: Fachtextsorten im Medienwechsel. In: Fachsprache, vol. 26, pp. 51-73. ISSN 10173285

ECO, U. 2006. Das offene Kunstwerk. Berlin: Suhrkamp. ISBN: 978-3-518-27822-2 EGOROVA, L.A., 2011. O probleme vospriyatiya nauchnogo gipermedijnogo diskursa. In: Vestnik RUDN, vol. 2, pp. 5-10. ISSN: 2312-9182

ENGELBARTH, D.C. 1995. Toward augmenting the human intellect and boosting our collective IQ. In: Communications of the ACM, vol. 38, n. 8, pp. 30-33. ISSN 00010782

ETKIND, A.M. 1979. Opyt teoreticheskoj interpretacii semanticheskogo differenciala. In: Voprosy psikhologii, vol. 1, pp. 17 - 27. ISSN: 0042-8841

FEDOROV, E.A. 1987. Kamennyj poyas. Moscow: Sovremennik.

FRUMKINA, R.M. 1984. Cvet, smysl, skhodstvo: aspekty psiholingvisticheskogo analiza. Moscow: Nauka Publishers.

GOSTEV, A.A. 2007. Psikhologiya vtorichnogo obraza. Moscow: Institut psikhologii RAN Publishres. ISBN 978-5-9270-0115-6

GRENANDER, U. - MILLER, M.I. 2007. Pattern theory: from representation to inference. Oxford: Oxford University Press. ISBN: 0198505701

HAUSSER, R.E. 2014. Foundations of Computational Linguistics. Berlin: Springer Berlin. ISBN 978-3-642-41430-5

HEISE, D.R. 1970. The semantic differential and attitude research. In: Summers, G.F. (Eds.) Attitude Measurement. Chicago: Rand McNally.

JAKOBOVITS, L.A. 1966. Comparative psycholinguistics in the study of cultures. In: International Journal of Psychology, vol. 1, pp. 15-37.

KUHLEN, R. 1991. Hypertext: Ein nicht-lineares Medium zwischen Buch und Wissensbank. Berlin: Springer-Verlag. ISBN 3-540-53566-7

LAKAN, J. 1997. Instanciya bukvy v bessoznatel'nom ili sud'ba razuma posle Frejda. Russkoe fenomenologicheskoe obshchestvo. Moscow: Logos. ISBN: 5-7333-0454-5 LANDOW, G.P. 2006. Hypertext 3.0: critical theory and new media in an era of globalization. Baltimore: Johns Hopkins University Press. ISBN: 0-8018-8256-7

LANHAM, R.A. 1993. The electronic word: literary study and the digital revolution. In: The Electronic Word. Democracy. Technology and the Arts. Chicago: University of Chicago Press. ISBN 0-226-46884-4

LEVANDOVSKIJ, N.G. 1980. O korrektnosti primeneniya faktornogo analiza. In: Voprosy psihologii, vol. 5, 138 - 142. ISSN 0042-8841

LOTMAN, Yu.M. 1992. Izbrannye stat'i. Tallinn: Aleksandra Publishers. ISBN 5450-01551-8

L'VOV, M.R. 2002. Slovar' antonimov russkogo yazyka. Moscow: AST-PRESS. ISBN: 5-7805-0625-6

MAMARDASHVILI, M.K. - Pyatigorskij, A.M. 1997. Simvol i soznanie. Metafizicheskie rassuzhdeniya o soznanii, simvolike i yazyke. Moscow: Yazyki russkoj kul'tury Publishers. ISBN 5-88766-055-4

MUKHIN, V.V. 1977. Ural. In: Bol'shaya Sovetskaya Enciklopediya, vol. 27, pp. 56 -60 .

MÜLLER, J.H. 1990. Versions of Pygmalion. Cambridge: Harvard UP. ISBN: 9780674934856

NELSON, T.H. 1992. Literary machines. California: Mindful Press. ISBN: 978-089347-062-3

NISBETT, R.E. 2003. The geography of thought: How Asians and Westerners think differently...and why. New York: Free Press. ISBN 0-7432-1646-6 
OSGOOD, C. - MIRON, M.S. - MAY, W.H. 1975. Cross-cultural universals of affective meaning. Illinois: University of Illinois Press, IL. ISBN 0-252-00426-4

PETRENKO, V.F. 2005. Osnovy psikhosemantiki. Saint-Petersburg: Piter. ISBN: 54690-0909-2

REID, T.M. 1957. Sobranie sochinenij v 6 tomakh. Moscow: Detgiz.

RYABOVA, M.E. 2007. Inoyazychie kak faktor razvitiya lichnosti: metodologiya razrabotki social'no-filosofskoj koncepcii. Saransk: Mordovskiy Universitet Publishers. ISBN 978-5-7103-1614-6

SHMELEV, A.G. 1982a. Ob ustojchivosti faktornoj struktury lichnostnogo semanticheskogo differenciala. In: Vestnik Mosovskogo universiteta, vol. 2, pp. 62 65. ISSN 0137-0936

SHMELEV, A.G. 1982b. Tradicionnaya psikhometrika i eksperimental'naya psikhosemantika: ob"ektivnaya i sub"ektivnaya paradigmy analiza dannykh. I: Voprosy psikhologii, vol. 5, pp. 34 - 46. ISSN: 0042-8841

SHMELEV, A.G. 1983. Vvedenie v eksperimental'nuyu psikhosemantiku: teoreticheskie i metodologicheskie osnovaniya i psikhodiagnosticheskie vozmozhnosti. Moscow: MSU Publishers.

TARASOV, E.F. 2000. Aktual'nye problemy analiza yazykovogo soznaniya. In: Ufimceva, N.V. Yazykovoe soznanie i obraz mira. Moscow: IYA RAN Publishers.

TERENT'EV, P.V. 1973. Zmei. In: Bol'shaya Sovetskaya Entsiklopediya, vol. 9, pp. 545-558. Moscow: Entsiklopediya.

USHAKOV, D.N. 2000. Tolkovyj slovar' russkogo yazyka. Moscow: AST. ISBN 57711-0015-3.

VASHUNINA, I.V. 2009. Vzaimodejstvie vizual'nyh i verbal'nyh sostavlyayushchih pri vospriyatii kreolizovannogo teksta. N. Novgorod: NGPU Publishers. ISBN: 978-585219-129-8

VVEDENSKAYA, L.A. 2004. Slovar' antonimov russkogo yazyka. Moscow: AST. ISBN: 5-2710-4336-3

WIRTH, U. 2002. Der Performanzbegriff im Spannungsfeld von Illokution, Iteration und Indexikalität. In: Performanz. Von der Sprachphilosophie zu den Kulturwissenschaften Suhrkamp. In: Frankfurt am Main, vol. 1 pp. 9-60. ISBN: 3518291750

ZABOLOTSKY, N.A. 1985. Stihotvoreniya. Moscow: Sovetskaya Rossiya.

ZINCHENKO, V.P. 2010. Soznanie i tvorcheskij akt. Moscow: Yazyki slavyanskih kul'tur Publishers. ISBN 978-5-9551-0437-9

Words: 7177

Characters: 49676 (27,60 standard pages)

Prof. Irina V. Vashunina, Dr. of Philology

Department of Foreign Languages in Theory and Practice

Institute of Foreign Languages,

Peoples' Friendship University of Russia

7 Miklukho-Maklaya st.

117198 Moscow

Russia

Vashunina@yandex.ru

Prof. Marina E. Ryabova, Dr. of Philosophy

Department of Foreign Languages in Theory and Practice

Institute of Foreign Languages,

Peoples' Friendship University of Russia

7 Miklukho-Maklaya st.

117198 Moscow 
Russia

Ryabovame@mail.ru

Assoc. Prof. Liudmila A. Egorova, PhD. in Philology

Department of Foreign Languages in Theory and Practice

Institute of Foreign Languages,

Peoples' Friendship University of Russia

7 Miklukho-Maklaya st.

117198 Moscow

Russia

Egorova_la@rudn.university, legorova@mail.ru 